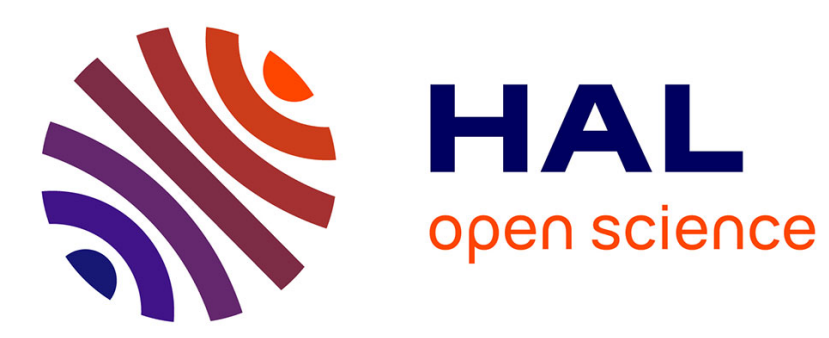

\title{
INTERNAL FRICTION CAUSED BY THE INTRINSIC PROPERTIES OF DISLOCATIONS
}

\author{
Gilbert Fantozzi, I. Ritchie
}

\section{To cite this version:}

Gilbert Fantozzi, I. Ritchie. INTERNAL FRICTION CAUSED BY THE INTRINSIC PROPERTIES OF DISLOCATIONS. Journal de Physique Colloques, 1981, 42 (C5), pp.C5-3-C5-23. 10.1051/jphyscol:1981501 . jpa-00220957

\section{HAL Id: jpa-00220957 https://hal.science/jpa-00220957}

Submitted on 1 Jan 1981

HAL is a multi-disciplinary open access archive for the deposit and dissemination of scientific research documents, whether they are published or not. The documents may come from teaching and research institutions in France or abroad, or from public or private research centers.
L'archive ouverte pluridisciplinaire HAL, est destinée au dépôt et à la diffusion de documents scientifiques de niveau recherche, publiés ou non, émanant des établissements d'enseignement et de recherche français ou étrangers, des laboratoires publics ou privés. 
JOURNAL DE PHYSIQUE

Colzoque C5, supplément au n¹0, Tome 42, octobre 1981

page $\mathrm{C} 5-3$

\title{
INTERNAL FRICTION CAUSED BY THE INTRINSIC PROPERTIES OF DISLOCATIONS
}

\author{
G. Fantozzi and I.G. Ritchie* \\ INSA, 69621 VizLeurbanne, France \\ *A.E.C.L.-W.N.R.E.Pincwa, Canada
}

Abstract.- Relaxation phenomena attributable to the intrinsic properties of dislocations are revievec. The principal theoretical rodels for the intrinsic dislocations relaxations and the Snoek-Köster relaxation are presented in outline. Recent important experinental resuits, i.ainly on f.c.c., h.c.p. and b.c.c. metals, are exanined and compared with the theoretical predictions.

1. Introduction.- In 1949, Borconi (1) observed an internal friction (IF) peak in f.c.c. metals which could only be attributed to dislocations and was associated with double-kink generation (DKG) by Seecer (2). From the relaxation enthalpy of Bordoni peaks, estimates of the Peierls stress can be obtained. The relatively high value found for the f.c.c's has persuaded several authors that the Bordoni peaks should not be attributed to DKG.

The objective of this paper is to review the experimental properties of the Bordoni relaxation (BR) in the f.c.c's together with their analogues in other structures, and to compare them with theoretical predictions. In the f.c.c's the situation seems clear and in the b.c.c's we can report the resolution of a long standing controversy about the role played by $H$ interstitials in the IF spectra of deformed samples. However, in the h.c.p's and b.c.c's some contradictions still exist.

2. Theoretical Aspects. - Several models for the $B R$ have been proposed and their essential characteristics are reviewed in detail elsewhere (3). Onty two of theri are generally retained to explain experimental data on the BR : DKG and geometrical kink migration (GKM). In the b.c.c's, the IF spectra of deforned samples of Mo, $W$ and $\alpha$-Fe are markedly different from those of samples of $V$, $\mathrm{i} b$, Ta and hydrogen charged $\alpha-F e$. This difference, which until recently has been the subject of a controversy, is attributable to the presence of $H$ interstitials with some dislocation core mobility giving rise to Snoek-köster ( $S-K)$ peaks. According to some authors $(4,5)$, at the atonic level, the $S-K(H)$ relaxation is due to the nodification of the DKG and GKM processes by the core mobile interstitials. Thus, it is important to outline tine models of the $s-k$ relaxation as well.

2.1 The DKG model. - The Seeger-Paré theory $(2,6)$ gives a good description of this mode1. Consider a dislocation segment (1) parallel to a Peierls valley (fig. 1). At $0 K$, the Peierls stress $\left(\sigma_{p}\right)$ is necessary to displace it. At $T>0$, under the combined influence of thermal fluctuations and the applied stress $\left(\sigma_{a}\right)$, DKG can occur. The IF due to DKG attains its maximum when the imposed frequency ( $f$ ) is of 
the same order of magnitude as the frequency $(v)$ of DKG:

PEERTS YALLEY.

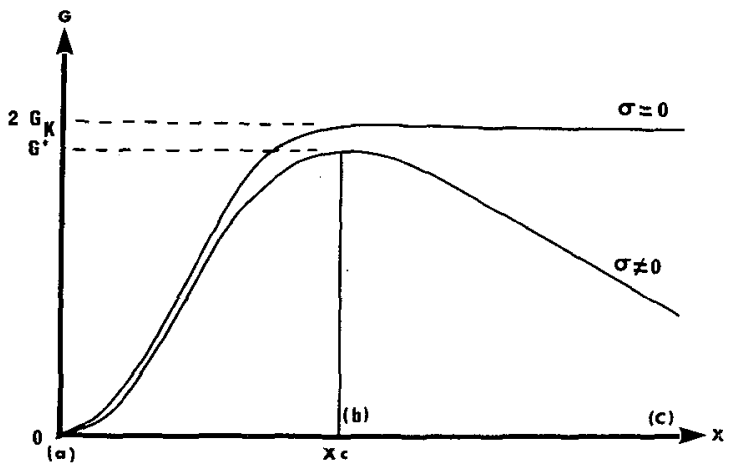

Fig. 1 : Left : schematic diagram of a dislocation overconing a Peierls barrier by creation of a double-kink : free energy of the double-kink as a function of kink separation $x$.

a) initial position of the line. b) the double-kink is created. c) the kinks glide along the line.

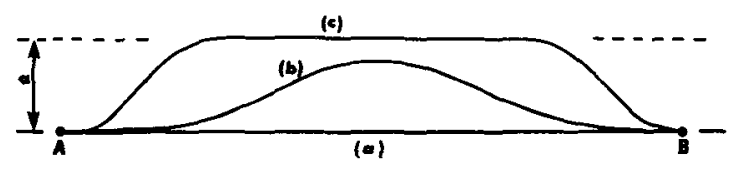

$$
v=v_{2} \exp \left(-2 w_{k} / k T\right)|1|
$$

where $2 W_{k}=$ formation energy of a kink pair, and $\nu_{l}$ is the eigenfrequency of the dislocation line.

In Seeger's model, the segment can be in either of two configurations (a) or (c). But with $\sigma=0$, configuration (c) has an energy $2 \mathrm{H}_{\mathrm{k}}$ greater than that of (a) (see fig. 1). Consequently, the occupation probability of (c) is very small and no relaxation peak will be observed. The relaxation strength only becomes observable when the exchange of dislocations between the two configurations is significant (i.e. if the two configurations are energetically equivalent).

For $\sigma \neq 0$, the two configurations can become equally probable when the Parê condition

$$
\sigma a b] \simeq 2 w_{k}
$$

is fulfilled. When $\sigma_{a}$ is weak, this condition can only be satisfied by the internal stress $\left(\sigma_{i}\right)$.

This theory accounts for the primary characteristics of the BR (2) but fails to explain the extent of peak broadening, the variation of peak temperature $\left(T_{M}\right)$ with microstructural state and non-linear effects (strain amplitude dependence and effects of bias stress). Dy including kink migration, Engelke (7) has shown that some of these seconciary features can be explained. However, Esnouf and Fantozzi $(3,0)$ have proposed a new approach to the calculation of IF caused by DKG. The energy diagram of a segment lying in a Peierls valley is detemined as a function of its position for áfferent values of $\sigma$ and $\ell$ (fig. 2). The activation volume $\left(v_{c}\right)$ and energy $\left(E_{c}\right)$ for double-kink nucleation depend only on $\sigma$ :

$$
E_{c}=2 w_{k}\left(1-\left(\frac{\sigma}{\sigma_{p}}\right)^{n}\right)
$$$$
v_{\mathrm{c}}^{\mathrm{m}} \sigma=\text { const. }
$$$$
n \simeq 3 / 4 \quad \mathrm{~m} \simeq 4
$$ 


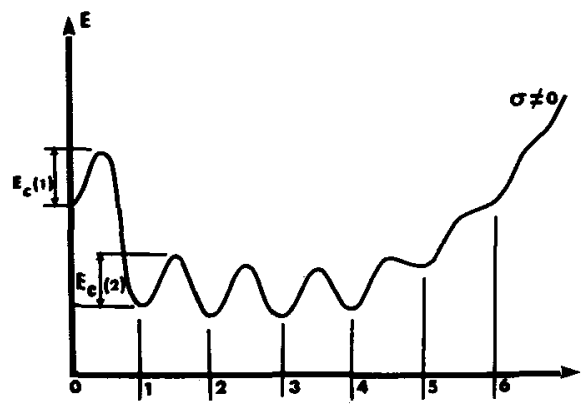

Fig. 2 : Potential Energy of the dislocation segment as a function of the number of double-kinks.
Kinetic theory is used to calculate the dislocation motion. The variation of the fraction $\left(n_{i}\right)$ of dislocations lying in the $\boldsymbol{j}$-th valley is given by :

$$
\begin{aligned}
& \frac{d n_{i}}{d t}=\Gamma_{i-1} n_{i-1}-\left(\Gamma_{i, i-1}+\Gamma_{i, i+1}\right) n_{i} \\
& +\Gamma_{i+1, i} n_{i+1}
\end{aligned}
$$

where the jump frequency from valley $i$ to $i+1$ is $\Gamma_{i, i+1}=v_{\ell} \exp \left(-E_{i, i+1} / k T\right)$ and $E_{i, i+1}$ etc are as specified in Fig. 2. The numerical solution of the above system, for an oscillating applied stress, allows calculation of the area swept-out by the dislocation and hence the IF. All of the characteristics of the $B R$ are explained by this model, without taking into account kink migration. By obtaining an effective dislocation mobility for DKG, Schlipf and Schindlmayr ( $($ ) have obtained similar results.

2.1.1 Peak height.- For a population of equal segments, when the Pare conơition is fulfilled, the intensity of the $B R$ varies as $\ell^{n}$ with $n \simeq 1$ for short segments and $n \simeq 2$ for long segments. For distributions of $\ell$ and $\sigma_{j}$, the peak height varies as $\ell^{2}$ for short segments. When the Pare condition is not satisfied, the variation of peak height is very pronounced. The exponent 2 shows that the area swept-out by the segment is controlled by the line tension $\left(E_{L}\right)$. In addition, the relaxation strength decreases with vibration frequency.

\subsubsection{Peak temperature.- $T_{M}$ depends upon $\sigma_{i}$ and $\ell$ (fig. 3 ). It is only} weakly dependent on $\ell$ for a

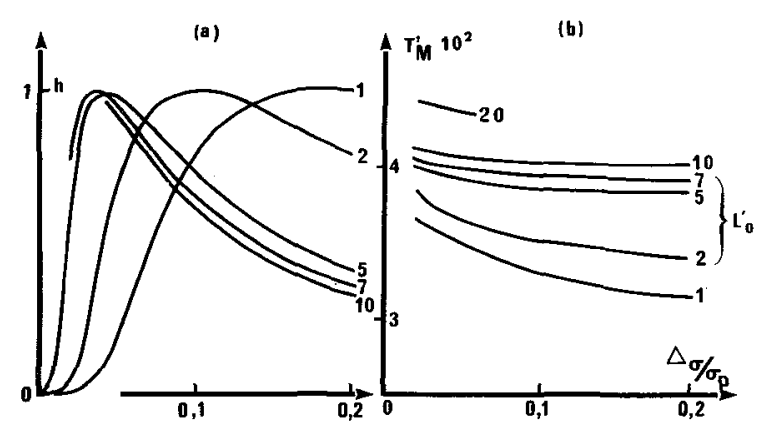

Fig.3 : Variation with mean deviation in internal distribution in $\ell$ only, but changes significantly for distributions of both $\ell$ and $\sigma_{i}$. These results show that the variation of the pre-exponential factor $\left(\tau_{0}\right)$ of the relaxation time with $\ell$ is given by : $\tau_{0} \sim \ell^{p}(0<p<2)$. The activation energy is near $E_{c}\left(\sigma_{i}\right)$.

stress for different mean normalized lengths $L_{o}^{\prime}\left(L_{o}^{\prime} \simeq 10^{-2} \mathrm{~L} / \mathrm{a}\right)$ : 
a) of the relative peak heighi

b) of the peak temperature $T_{i}(3)$.

2.1.3 Broadening fiactor.- Distribution of $\tau_{0}$ and/cr the activation energy cause peak broadening. It can be up to four times the factor for a lebye peak. Furthermore, the high temperature part of the peak (due to the longest segrients) is more developed than the rest of tine peak.

2.1.4 Nion-linear effects.-

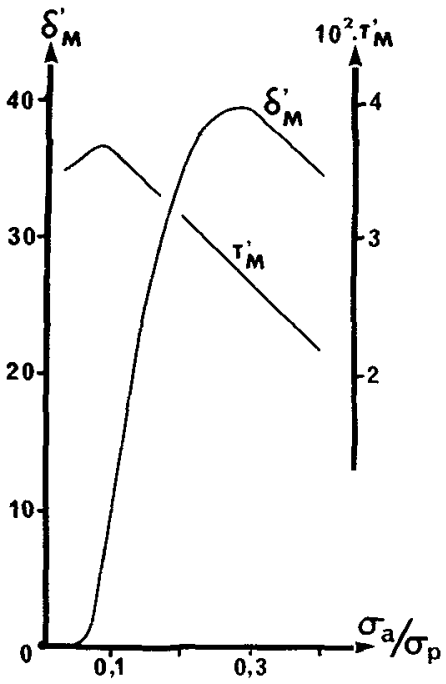
When $\sigma_{i}$ is too small to satisfy the Parë concijtion, the peak can still develop and pass through a maximum as the applied stress (oscillating or static bias) increases (fig. 4). Horeover, the peak shifts to lower temperature and broadens with increasing $\sigma_{a}$. Similarly, the relaxation strength presents a maximum as a function of $\sigma_{i}$ (Fig. 3). The increase in peak height is due to the Pare condition, the decrease results frof: the reduction of swept-out area when the number of double-kinks increases.

Fig. 4.: Variacion of peak height

$\delta_{i}^{\prime}$ and temperature $T_{i}^{\prime}$ as a function of $\sigma_{a}$ (for $L^{i}=7$ and $\sigma_{i}=0$ )

2.2 The GWI node1.- Geometrical kinks moving along close-paoked directions can be thermally activated over the second

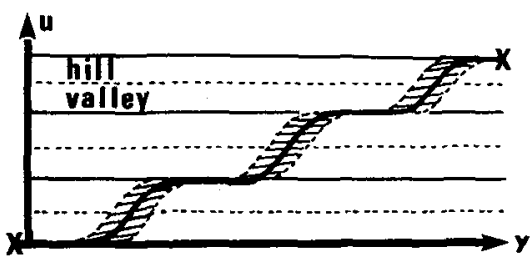

Fig. 5 : Geonetrical kink notion on a dislocation making an angle $\Psi$ with a close-packeù direction. order Peieris Darriers giving rise to an If phenowenon as siown by Braitsford (10) and Uuthrich (11). An applied stress causes akg (fig. 5) given by : $\frac{\partial u}{\partial i}-D_{k} \frac{\partial^{2} u}{\partial y^{2}}=\sigma a^{2} b$ in $n_{k}$ $n=\bar{v}_{k} / k T=v_{d} b^{2} \exp \left(-W_{H} / k T\right)$ where $m=$ kink nobilicy, $v_{d}=$ Debye frecuenc:,$W_{M}=$ kink wigration enercy 
and $n_{k}$ the number of geonetrical kinks per unit length.

Solution of the above equation yields the relaxation sirength $(\Delta)$ and tive ( $\tau)$ of the IF peak :

$$
\Delta=4 \mu \frac{a^{2} b^{2}}{\Pi^{2} k T} \Lambda l^{2} n_{k} ; \tau=\frac{l^{2}}{\nu_{D} b^{2} \Pi^{2}} \exp \left(W_{M} / k T\right)
$$

$\mu$ is the shear rociulus and $\Lambda$ the dislocation density. The $2^{2}$ depencience of is due to behaviour analogous to a stretcheó string behaviour (3).

The GKM model can account for nost of the BR characteristics. Distributions of $\ell$ and $\Psi$ (fig. 5) leac to broadening of $\approx 1.5$. This is due to distribution of $\tau$ but not the activation energy (unlike $D K G$ ). Another inportanit prediction is that $\tau_{0}\left(\geq 10^{4} / \nu\right)$ for GKit is two orders of ragnitucie higher than $\tau_{0}\left(\sim 10^{2} / \nu_{0}\right)$ for DKa. Unlike OKG, a well-defined stress level is not recuired to observe a decrease in $\Delta$ when stress $\left(\sigma>\frac{\mu b \sin \psi}{\ell}\right)$ induces a pile-up of geometrical kinks.

2.3 The S-K relaxation.- $S-K(X)$ relaxations where $X$ is an ispurity interstitial (II) are well established in the IF spectra of deformed b.c.c's. A phenomenological model proposed by Schoeck (12) has been used with varying degrees of success to explain the experimental results. It is based on the cragging of II's by stringlike dislocation segments (fig. 6a). The relaxation time $\left(\tau_{S K}\right)$ and strength $\left(\Delta_{S K}\right)$ found using this model for a dilute concentration $\left(C_{d}\right)$ of II's on the dislocations are given by :

$$
\tau_{S K}=\alpha k T L_{0}^{2} C_{d} \exp \left(i_{S K} / k T\right) ; \Delta_{S K}=\beta \Lambda L_{0}^{2}
$$

and the relaxation enthalpy $\left(H_{S K}\right)$ by : $H_{S K}=H^{B}+H^{H^{\prime}}$

In these equations, $L_{0}$

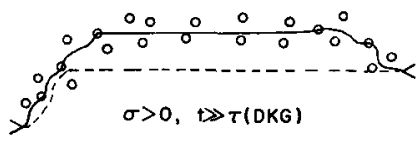

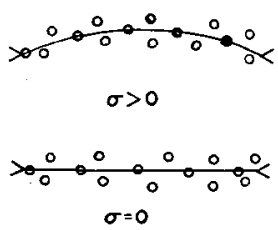

a
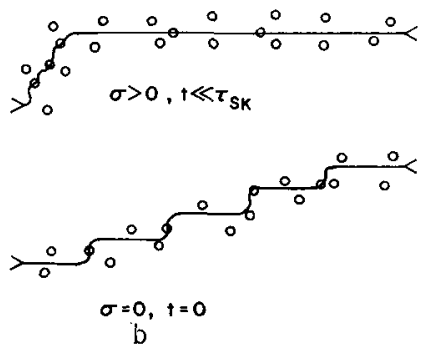
is the mean segment length, $\mathrm{H}^{\mathrm{B}}$ the binaing enthalpy of tine II's to the dislocations, $\mathrm{H}^{\mathrm{M}}$ the rigration enthalpy of the II's at the dislocations $\left(H^{M}\right.$ is the same quantity in the lattice) and $\alpha, \beta$ are numerical constants. When the cores are saturated, $\mathrm{H}_{\mathrm{SK}}$ reduces to $\mathrm{H}^{\mathrm{M}}$. Recently,

Fig. 6 : Models of the S-K relaxation : a) string model. Verdini and Bacci (13) b) double-kink generation in the presence of core-mobile impurity interstitials.

have developed a modification of the model which 
takes into account the dissipation associated with bow-out between the II's. They show that $\Delta_{S K}$ becomes dependent on $C_{d}$ (below saturation) and that $H_{S K}=2 H^{B}+H^{M}$. Other modifications have been reported. For example, Miner et al. (14) have shown that when the occupation probabilities of the pinning sites are nore correctly treated by Fermi-Dirac statistics, $\mathrm{H}_{S K}$ can take on values between $\mathrm{H}^{\mathrm{B}}+\mathrm{H}^{\mathrm{I} \mathrm{H}^{\prime}}$ and $2 \mathrm{H}^{\mathrm{B}}+\mathrm{H}^{\mathrm{H}^{\prime}}$. Fron many comparisons of the predictions of Schoeck's model with experiment, there is little donbt that several aspects of the model are correct.

Seeger (4) abbributes $S-K(X)$ to DKG in the presence of core mobile $X$ interstitials (fig. 6b). In this model, with the exception of the numerical constanis, equ. $|7|$ is unchanged, while the relaxation enthalpy becomes :

$$
\mathrm{H}_{\mathrm{SK}}=2 \mathrm{H}_{\mathrm{K}}+\mathrm{H}^{\mathrm{BH}}
$$

where $2 H_{k}$ is the formation enthalpy of a kink pair. Hirth (5) considering the special case of $\mathrm{S}-\mathrm{K}(\mathrm{H})$ in $\alpha-\mathrm{Fe}$, has developed a similar nodel for the case of near saturation. He finc's

$$
H_{S K}=2 H_{k}+H^{M '}-\left(\mu \sigma b^{6} / 2 m\right)^{1 / 2}
$$

At the stress levels normaliy involved eqns $|\rho|$ and $\mid 10 !$ becone pratically idientica1. However, the lasi tern does give an explicit dependence on $\sigma$ (and hence $\sigma_{i}$ ) which can account for the broadening of the $S-K$ peaks. The most important point to establish is which of the predictions, eqn. $|\delta|$ (or its modifications) or eqn. $|9|$ (or $|10|)$ comes closest to representing the experimental values of $\mathrm{H}_{S K}$.

3. Importani Experimental Results.- Our task in this section is to exaraine the important experimental results on the intrinsic relaxations of dislocations in metals and to try to interpret them with the models outlined in section 2. Results published up to the time of the Manchester conference (1979) have been reviewed recently ( 3$)$, so we will concentrate mainly on more recent results.

3.1 F.C.C. and H.C.P. metals.- The $B R$ in these metals is usually composed of two IF peaks: $\hat{B}_{1}$ (the Wiblett and Wilks peak) and $B_{2}$ (the Bordoni peak. In metals of ordinary purity the $B R$ is not observed in annealed specimens and only appears after plastic deformation. In ultra high purity (UHP) samples, the $B R$ is always observed, even after recrystallization, but depends strongly on the applied stress. This is shown on fig. 7 for $\mathrm{Pb}(15)$ and on fig. 8 for $\mathrm{Ag}(16)$. Thus the disappearance of the BR in non-UHP metals after recrystallization is not due solely to the decrease in $\Lambda$ but also to pinning by impurities. This shows that the $B R$ can only be attributed to the intrinsic properties of dislocations, i.e. GKM and/or DKG. 


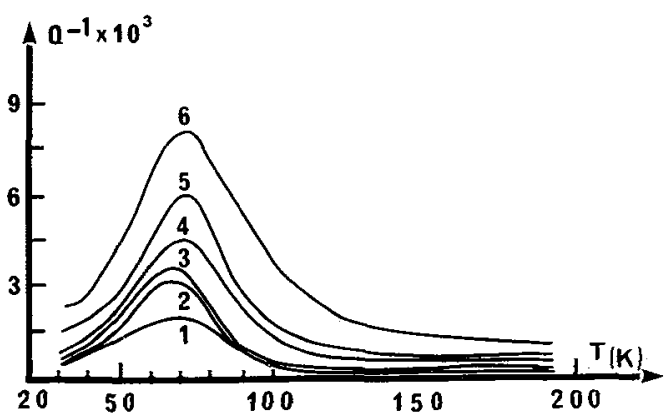

Fig. 8 : Evolution of the $B R$ during recrystallisation at $200^{\circ} \mathrm{C}$ in $6 \mathrm{~N}$ silver cold-rolled $6 \%$ at $20^{\circ} \mathrm{C}\left(\varepsilon_{\mathrm{nin}}=2.5 \times 10^{-7}\right): 1$, Omin; $2,10 \mathrm{mn}$; $3,30 \mathrm{mn} ; 4,60 \mathrm{mn} ; 5,120 \mathrm{mn} ; 6,840 \mathrm{mn}(16)$.

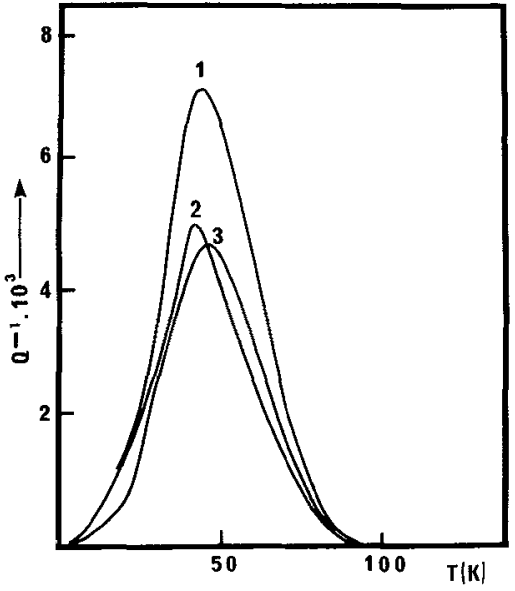

Fig. 7 : Evolution of the $\mathrm{SR}$ in $\mathrm{Pb}$ : 1 , unannealed; 2 , annealed at $870 \mathrm{~K}$; 3 , at $550 \mathrm{~K}(15)$.

3.1.1 Peak height.- The peak height varies with impurity content, conditions of plastic deforiation, annealing and irradiation. This variation is inked to the evolution of $\ell$ and is of the form $\ell^{r}$ with $1 \leqslant r \leqslant 2$.

3.1.2 Peak temperature.- The peak teinperature varies slightly with the microstructural state and is caused essentially by a depencience of $\tau$ on $l\left(\propto l^{S}\right.$ with s lying between 1 and 4) $(3,17)$. This variation explains the large dispersion of the data in Arrhenius plots.

3.1.3 Broadening factor.- The peaks are generally two to four times broader tnan a Jebye peak, i.e. $\tau$ is distributed. The $y^{\prime}$ are broader for small anounts of plastic defornation, with the increase in width more pronounced on the high temperatures sicies. In contrast, annealing decreases the widths by reducing the high temperature sides preferentially. This asymetry in the recuction of the wicth is shown by the aifferences in the If curves for slightly deformed Al in fig. 9 (18). 


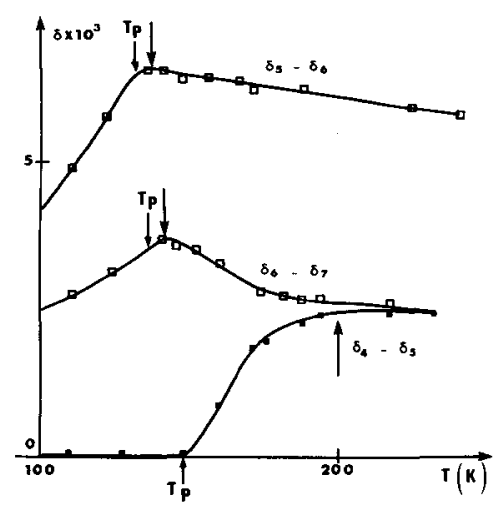

Fig. 9 : the difference $\delta_{n}-\delta_{n+1}$ between the curve obtained curing the linear warmup, $n$, and that obtained curing the linear warm-up, $n+1$, after flexural deformation of $0.2 \%$ at $80 k$ ( $n=3$, annealing temperature $T_{R}=222 \mathrm{~K} ; n=4, T_{R}=240 \mathrm{~K} ; n=5, T_{R}=$ $\left.285 \mathrm{~K} ; n=6, T_{R}=314 \mathrm{~K}\right)$. The short arrow indicates the peak temperature of $B_{2}$, while the long arrow indicates the temperature of the maximum of $\delta_{n}-\delta_{n+1}(18)$.

3.1.4 Non-Linear Efiects.- When $\sigma_{j}$ is significant (after large plastic deformation), $\sigma_{a}$ has little effect (fig. 1\%). However, for weak $\sigma_{i}$
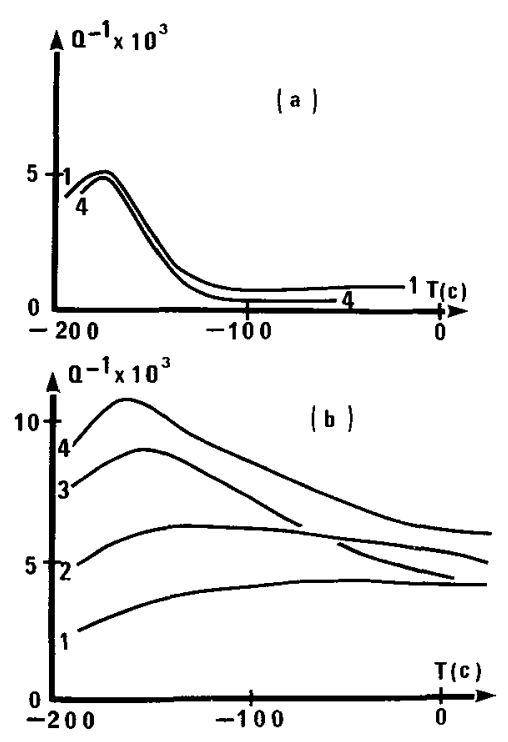

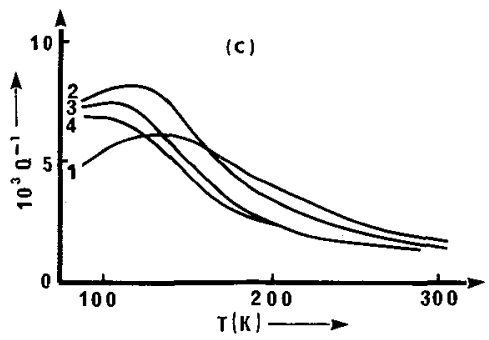

Fig. 10.: Internal friction in gold colci-workeci $7 \%$ at $20^{\circ} \mathrm{C}$ : a) arter cieformation, b) arter annealing 60 min at $350^{\circ} \mathrm{C}$. Oscillating strain amplitucie : (1) $\varepsilon_{\mathrm{m}}=4 \times 10^{-7}$, (2) $15 \times 10^{-6}$, (3) $6 \times 10^{-6},(4)$ $5 \times 10^{-5}$. c) Internal friction in gold cold-worked $62 \%$ and annealeci $60 \mathrm{~min}$ at $165^{\circ} \mathrm{C}$.

(1) $\varepsilon_{m}=3 \times 10^{-7}$, (2) $1.5 \times 10^{-6}$, (3) $6 \times 10^{-6},(4) 1.5 \times 10^{-5}$ (19). 
important non-1inear effects are observed (Fig. 10).: the relaxation strength depends strongly on $\sigma_{a}$ (periodic or static). Similar results have been observed by many authors (3). The $B R$ intensity increases consicierably with the vibracion anplitude or static stress. Moreover, the renoval of the $B R$ during recovery or recrystallization is caused by a decrease of $\sigma_{j}$. In some cases, the peak height passes through a maximum as a function of the strain amplitude. In Mg, significant nonlinear effects are observed after plastic deformation when only one slip system is activated (20). As shown in fig. 11, the peak heights of boith $B_{1}$ and $B_{2}$ pass through a maximum as the superimposed bias stress is increased.
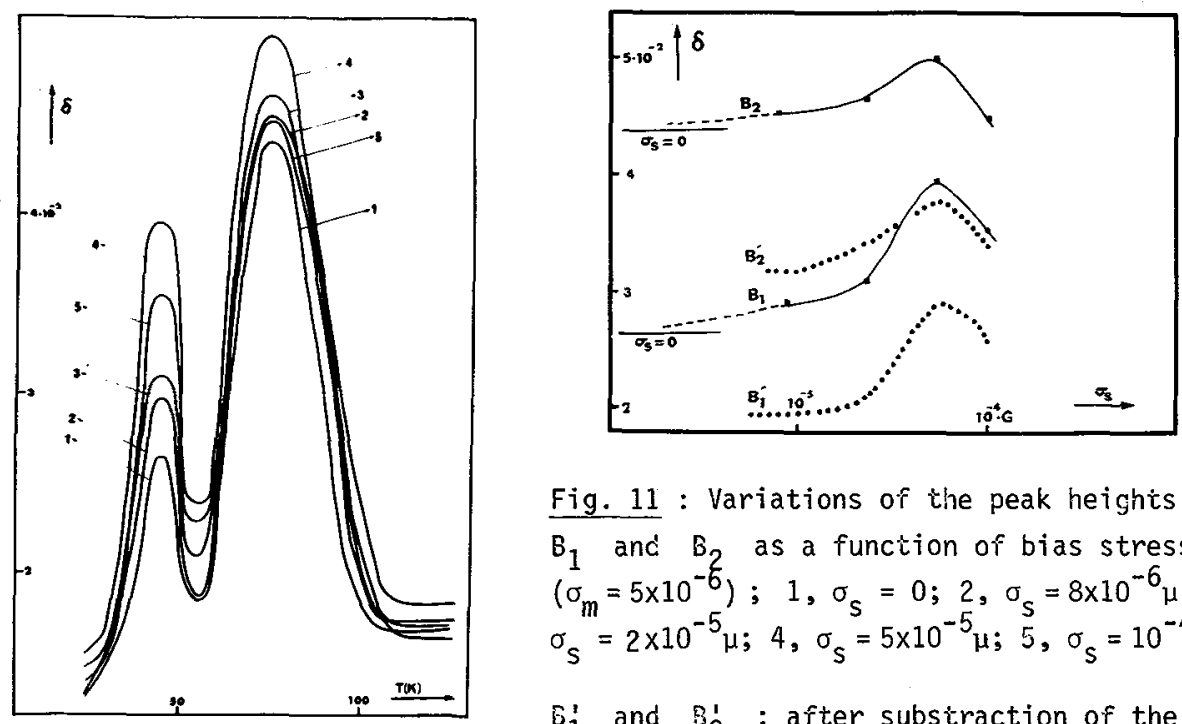

Fig. 11 : Variations of the peak heights of $B_{1}$ and $B_{2}$ as a function of bias stress $\sigma_{s}$ $\left(\sigma_{m}=5 \times 10^{-6}\right) ; 1, \sigma_{s}=0 ; 2, \sigma_{s}=8 \times 10^{-6} \mu ; 3$, $\sigma_{s}=2 \times 10^{-5} \mu ; 4, \sigma_{s}=5 \times 10^{-5} \mu ; 5, \sigma_{s}=10^{-4} \mu$.

$B_{1}^{\prime}$ and $B_{2}^{\prime}$ : after substraction of the background $(20)$.

3.1.5 Low Teinperature Modulus Defect.- In both f.c.c's and h.c.p's, there is a modulus cefect at tenperatures lower than the ER. Consequently, aisis, on at least one of the dislocation types, must be reserved to explain this phenomenon.

3.1 .6 Dislocation types.- Seeger (2) proposed that non-screw dislocation segments (I's) give rise to $B_{1}$ and screws ( $\theta$ 's) give rise to $B_{2}$, since the Peierls energy for $\theta^{\prime} s$ is higher than that for L's. This is supported by observations that $B_{1}$ is more sensitive to pinning by point defects than $B_{2}$. However, recent electron microscopy studies by Lauzier and iinier (21) support an earlier hypothesis of Thompson and Holnes (22), i.e. $B_{1}$ is associated with $90^{\circ}$ and $30^{\circ}$ dislocations lying along <112> direction and $B_{2}$ is associated with $60^{\circ}$ and screw dislocations lying along $\langle 11 \hat{0}\rangle$ direction. The $\theta$ 's are responsible for the nigh teriperature component of $B_{2}$ whereas the $60^{\circ}$ dislocations are responsible for the low temperacure component. This nypothesis allows us to explain the variation of 
the peak tenperature during irradiation or annealing (21) and also accounts for the two peaks $X$ and $Y$ observed in deformed $N i$ (23) : peak $X$ may be the analogue of $B_{2}$ and $Y$ the analogue of $B_{1}$. Besson (23) proposed that $Y$ was caused by dissociated forms of the same dislocations responsible for $X$. The Thompson and Holmes hypothesis is more plausible and does not necessitate the assumption of an increase in dissociation with plastic deforation. Nevertheless, the rôle of stacking fault energy in the $B R$ remains to be elucidated. In $\mathrm{Hg}$, Seyed-Reihani (20) has shown that results lead to a conclusion in keeping with Thoripson and Holmes hypothesis also.

3.1.7 Corment.- Although the BR has been observed in several h.c.p's, only in Ulif $\mathrm{Mg}(20)$ have $B_{1}$ and $B_{2}$ peaks with properties comparable to those in the f.c.c's been reported. We conclude that f.c.c's and h.c.p's behave similarly (3). Nevertheless, further studies on other UHP h.c.p's will be necessary to confirm this point.

3.1.8 Interpretation.- Only the DKG model accounts for a11 of the experimental characteristics of the $3 i$ as can be seen frori a direct comparison of sections 2.1.1. to 2.1.4. with sections 3.1.1. to 3.1.4. Nevertheless, the value of $\sigma_{p}$ obtained from the relaxation enthalpy of the $B R\left(10^{-3}-10^{-4} \mu\right)$ is considerabiy greater than that predicted from plastic behaviour and so, the DKG model for the BR is still contested $(3,17)$. Two relatively new types of experiment also support the LKü model. Firstiy, measurements of ultrasonic attenuation at very low temperatures denonstrate GKM (24) : the attenuation decreases as the bias stress increases (fig. 12). This "stiffening" phenomenon is due to the pile-up of geometrical kinks

in response to the bias

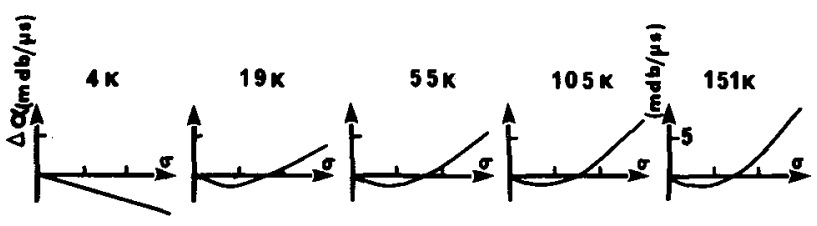

Fig. 12 : Variation of attenuation versus stress at different testing temperatures in $\mathrm{Al}(2 \mathrm{4})$. stress (25). In the temperature range of the $B R$, dislocation segnents surmount the Peierls barriers and the attenuation increases with bias stress (fig. 12). Sone different results were reported recentiy (26) but remain to be confirmed. Secondly, a thermally activated microdeformation stage $(3,27)$ associated with the $3 R$ has been observed in Al, Au and $\mathrm{Ig}$ (fig. 13) torether with a variation in the anelastic limit (27). A quantitative analysis of these results yields an activation energy of $\sim 0.1 \mathrm{eV}$ and a volume of $\sim 10 \mathrm{C} \mathrm{b}^{3}$ entirely in keeping with the DKG model (27).

In conclusion, the experinental results strongly support the existence of a Peierls-ilabarro stress in the f.c.c and h.c.p metal of $10^{-3}$ to $10^{-4} \mu$. 

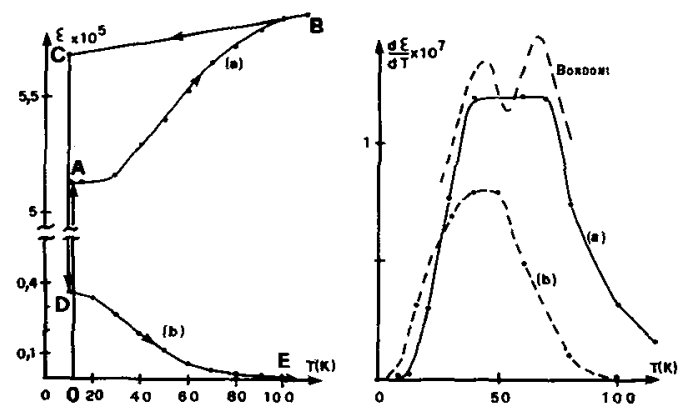

Fig. 13 : Microdefornation (and derivative curve) as a function of temperature for a $6 \mathrm{~N}$ gold sample, deformed $0.7 \%$ in torsion at $10 \mathrm{~K}$ and annealed at $150 \mathrm{~K}$ : (a) with a static stress $\sigma=5 \times 10^{-4}$, (b) after suppression of the stress at $10 \mathrm{~K}(3)$.

3.2 B.C.C. Metals.- The intrinsic dislocations relaxations in the b.c.c's are of special interest because the mobilities of $L^{\prime} s$ and $\theta^{\prime} s$ are such that the analogue of the Bordoni relaxation is split into two well-separated peaks $(28,29)$ : a low temperature peak associated with DKG ( $($ ) and a peak at a much higher temperature associated with DKG $(\Theta)$. Moreover, geometrical kinks on $\theta^{\prime}$ s are expected to be rather abrupt (effectively high second order Peierls barriers (30)) so that GKil $(\theta)$ should fall into a teraperature range close to that for DKG ( $D$. As in the case of the f.c.c's, GKM ( $)$ is expected to occur at very low temperatures $(<4 \mathrm{~K})$ and manifest itself as a modulus defect at the lowest temperatures investigated. These expectations seem to be realized in $M, k$ and $\alpha-F e$ as typified by the IFS of a deformed single crystal of Mo $(31,32)$ in fig. 14. In contrast, in $V, N b$

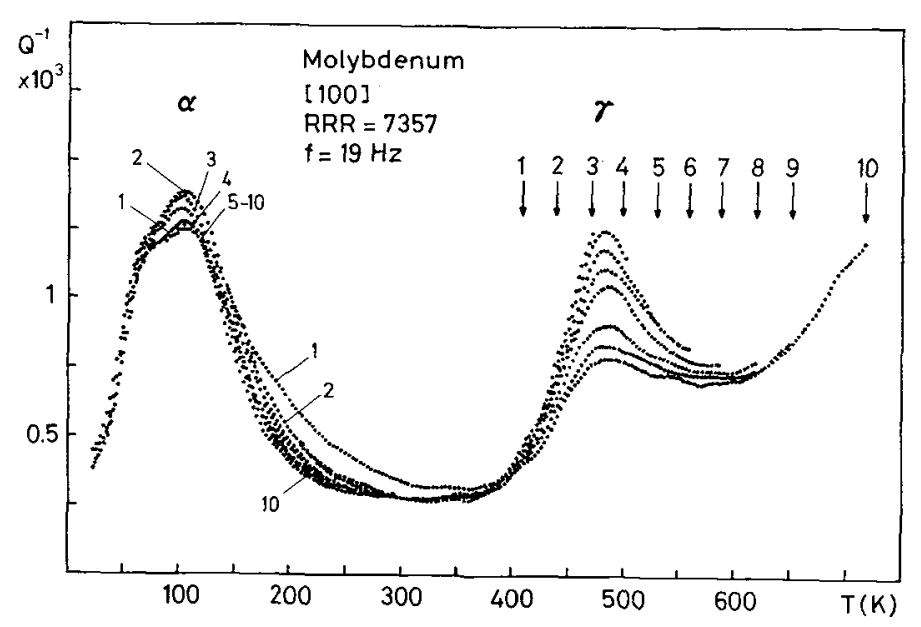

Fig. 14 : Internal friction spectrum of a deformed crystal of Mo. Plastically strained $1 \%$ at $200 \mathrm{~K}+$ a small additionnal plastic strain in torsion at $295 \mathrm{~K}$ (31). and $\mathrm{Ta}$ (also $\alpha-\mathrm{Fe}+\mathrm{H}$ ) the IFS is characterized by a larger number of peaks. Typical reresults for a deformed single crystal of $\mathrm{Ta}$ (33) are shown in fig. 15 where the IFS is resolved into 7 component peaks with oniy one of them attributed (by the authors) to the intrinsic dislocation processes discussed above; the others are attributed to the interactions of dislocations with II's. 


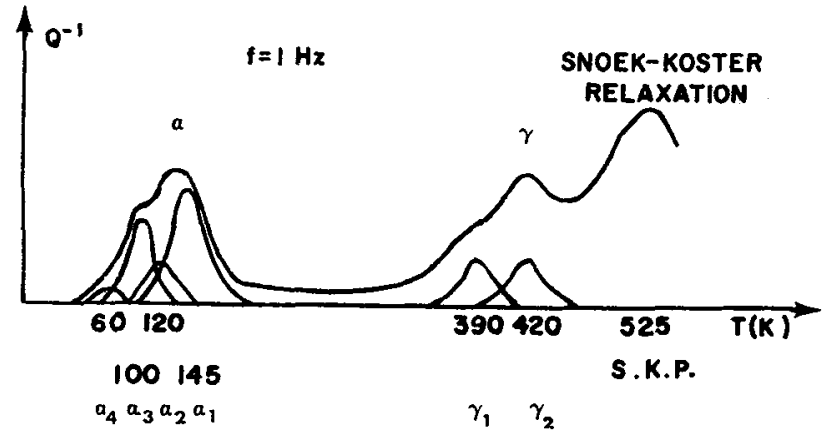

Most of the differences between the f.c.c's and b.c.c's can be traced to the strong interactions between residual II's ( $\mathrm{H}, \mathrm{N}$, O or ( atoms) with the dislocations in b.c.c's. In fact, these interactions can lead to diametrical1y opposed changes in properties, e.g.

Fig. 15: Internal friction spectrum of a deformed single crys-hardening through tal of Ta. Deformation history : $3.1 \%$ tensile strain at the interactions of $375 K+0.5 \%$ tensile strain at $200 \mathrm{~K}+\mathrm{a}$ small additional plas- II's with $\perp^{\prime} \mathrm{s}$ and tic strain in torsion at $295 \mathrm{~K}(33)$. softening through their interactions with $\theta^{\prime} s$ (see review by Pink and Arsenault (34)). The presence of trace amounts of $H$ in deformed $V, N b$ and $\mathrm{Ta}$ samples has led to a controversy over the interpretation of the IFS in these metals which has been resolved recently.

3.2.1 A Controversy Resolved.- The IFS of deformed $\mathrm{V}, \mathrm{Nb}$ or $\mathrm{Ta}$ is generally characterized by a group of relaxations in the range 120-200K (e.g. fig. 15) labelled $\alpha$ by most workers $(35,36)$. However, a peak labelled $\delta$, at even lower temperatures, is observed in some samples $(35,37)$. As suggested by Bruner $(38)$, the Rome school $(35,37)$. has argued that $\alpha$ requires the presence of both $H$ and dislocations and that $\delta$ can be attributed to intrinsic disiocation processes. This interpretation was contested by the Stuttgart School who studied samples with considerably lower II concentrations and observed neither $\delta$ nor any indication of dislocation movement below $\alpha$, leading them to attribute $\alpha$ to intrinsic dislocation processes. Nevertheless, over the last few years, evidence that $\alpha$ involved $H$ began to accumulate : notably from Shibata et a1. (39) and Mizubayashi et a1. (40) for V, Ferron et a1. (41), Kuramochi et al. (42) and Verdini and Bacci (43) for $\mathrm{Nb}$ and Rodrian (33) for Ta. Yet, no explanation for the absence of $\delta$ in samples with lower II (particularly 0) contents was offered. More recently, work on UHP Nb $(31,44,45)$ has demonstrated that $\alpha$ involves $H$ and that the major component can be attributed to an $S-K(H)$ relaxation (43). In the highest purity samples $\left(C_{H} \ll 1\right.$ at. p.p.m, $C_{0}<5$ at. p.p.m), the work at Stuttgart $(31,44,45)$ has shown that another peak appears below $\alpha(\sim 70 \mathrm{~K}$ as shown in fig. 16). But, in order to completely settle the controversy, it is necessary to show that the $70 \mathrm{~K}$ peak is equivalent to $\delta$. In an attempt to do this, Maul (45) repeated measurement on sam- 
ples doped with 0 and $H\left(C_{0}=800-1000\right.$ at, p.p.m and $C_{H}=20-30$ at. p.p.m). The results are shown in Fig. 17 and compared directly with $\delta$ (35).

It is clear that in

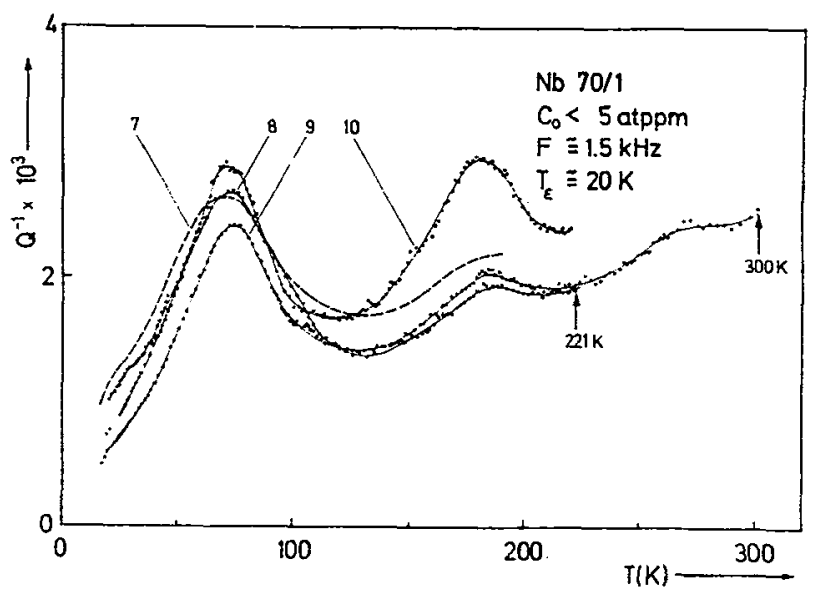

Fig. 16 : Internal friction of a single crystal of $\mathrm{Nb}$ after a thorough degassing $\left(\mathrm{C}_{H} \ll 1\right.$ at. p.p.m) and deformation at $20 \mathrm{~K}(45)$.

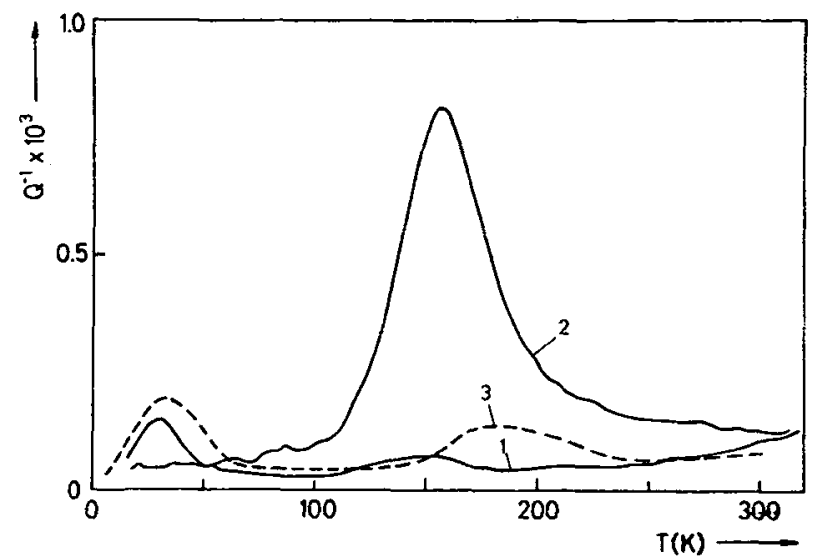

Fig. 17 : Internal friction in a doped $\mathrm{Nb}$ single crystal $\left(C_{0}=800-1000\right.$ at. p.p.m). 1, after deformation 2 after $H$ charging to $C_{H} \approx 20-30$ at. p.p.m; 3 , results of Mazzolai and Nuovo $(35,45)$.

ii) the relaxation parameters of $\delta$ are more consistent with GKM $(\theta)$ than DKG ( 1 ) (section 3.2 .4 ); iii) results on thoroughly outgassed $V(40)$ appear to exhibit both 
peaks in the same spectrum, while the higher temperature peak is absent in samples outgassed to a lesser extent; iv) $\alpha$ (attributed to DKG $(\perp$ ) in $\alpha-F e$ ) cannot be generated in the presence of only $\sim 20$ at. p.p.m of $C$ or $N(46)$.

\subsubsection{S-K $(H)$ Peaks.- It is interesting to examine the predictions of the} models outlined in section 2-3 for the case of the $S-K(H)$ in $\alpha-F e: i)$ because it is the most thoroughly investigated $S-K(H)$ and $i i)$ because it is similar in most respects to the $S-K(H)$ (labelled $\alpha$ ) in $V, N b$ and $T a$. To check the validity of eqns $|8|$ and $|9|$ we must compare the experimental values of $H_{S K}$ (ranging from 0.11 to $0.33 \mathrm{eV})(47-50)$ with $H^{B}\left(D+H^{M^{\prime}}\right.$ and $2 H_{k}(L)+H^{M^{\prime}}$. From studies of peak $\alpha$ in $\mathrm{Fe}, 2 \mathrm{H}_{\mathrm{k}}$ ( ( ) is in the range 0.04 to $0.06 \mathrm{eV}(48,50,51)$, while the most probable value of $H^{B}\left(D\right.$ is $0.61 \mathrm{eV}(52)$. Whether we take $H^{M^{\prime}} \simeq H^{M}$ (following Seeger (4)) or $H^{M^{\prime}} \cong H^{M} / 2$ (following Hirth (5)), since the values of $H^{M}$ currently advocated by various reviewers 7 ie in the range 0.042 to $0.069 \mathrm{eV}(53,54)$, no combination of the data seems to be consistent with either the Schoeck model, eqn. $|8|$, or the Seeger or Hirth models, eqn. $|9|$, unless the lower bound of $H_{S K}$ (found in a series of magnetic after-effect studies only) is compared with the upper bound of $2 \mathrm{H}_{\mathrm{K}}(\mathrm{\perp})+\mathrm{H}^{\mathrm{M}^{\prime}}$ as pointed out by Kê et al. (49). We suggest that this very unsatisfactory situation arises because $2 H_{k}(\perp)$ is effectively increased in the presence of $H$. This is consistent with the viewpoint expressed by Hirth (5) who attributes the $S-K(H)$ in Fe to a combination of hardened L's and softened $\theta^{\prime} s$.

3.2.3 Classification of the IF Peaks.- From the above, it is clear that the labelling of the peaks in the IFS of a deformed b.c.c. has become confusing. We propose that the labelling should be modified in the manner shown in table 1 to retain as much of the traditionnal classification scheme (3) as possible, yet to reflect the mechanisms involved, rather than simply the temperature ranges in which the peaks occur.

\subsubsection{Other Recent Experimental Results.- From fig. 14, it is clear that} in UHP deformed b.c.c's the IFS consists of a low temperature group of peaks and a high temperature peak. The low temperature group is generally attributed to one or both of the $\alpha^{\prime}(\theta)$ and $\alpha$ processes; the high temperautre peak is attributed to the $\gamma$ process. In the following, we refer to them simply as $\alpha^{\prime} / \alpha$ and $\gamma$ respectively. Evidence for the presence of at least two discrete relaxations in $\alpha^{\prime} / \alpha$ consists of the marked asymmetry or shoulder which appears on the low temperature side of the peak and a corresponding step in the modulus curve. Four such steps have been reported for the lowest temperature peak in $V(40)$. This is similar to the stepped modulus curves associated with the BR (3).

a) Relaxation Parameters.- Activation parameters from the peak shift of $\alpha^{1} / \alpha$ with frequency fall into two groups : for $V(37)$, $\mathrm{Nb}(43,55)$ and $\mathrm{Ta}(35)$ the activation energy falls in the range 0.012 to $0.047 \mathrm{eV}$ and the pre-exponential factor falls into the range $10^{-9}$ to $2 \times 10^{-8} \mathrm{~s}$; for Mo $(3,32), W(3)$ and $\alpha$-Fe $(51,46)$, the 
equivalent ranges are 0.04 to $0.29 \mathrm{eV}$ and $1.4 \times 10^{-14}$ to $5 \times 10^{-10} \mathrm{~s}$. The first set, i.e. the old $\delta$ peaks, seems to be consistent with GKM $(\theta)$; while the second set seems to be more consistent with DKG ( 1 ). It will be interesting to see how the relaxation parameters of the recently discovered $70 \mathrm{~K}$ peak in $\mathrm{Nb}$ and the 57 in $V$ compare with those of the old $\delta$ peaks.

TABLE 1

\section{CLASSIFICATION SCHEME FOR THE IF PEAKS IN DEFORMED BCC METALS.}

\begin{tabular}{|c|c|c|c|}
\hline \multicolumn{2}{|c|}{ PROCESS } & OLD LABEL(S) & NEW LABEL \\
\hline $\begin{array}{l}\text { INTRINSIC } \\
\text { DISLOCATION } \\
\text { LOW TEMP. }\end{array}$ & 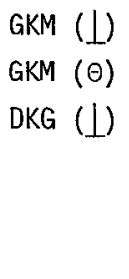 & $\left.\begin{array}{l}\alpha^{\prime} \\
\alpha^{\prime} \quad \alpha_{2} \\
\alpha(\mathrm{Mo}, \mathrm{W}, \mathrm{Fe}) \\
\delta(\mathrm{V}, \mathrm{Nb}, \mathrm{Ta}) \\
57 \mathrm{~K}(\mathrm{~V}) \\
70 \mathrm{~K}(\mathrm{Nb})\end{array}\right\}$ & $\left.\begin{array}{l}\alpha^{\prime}(\perp) \\
\alpha_{i}^{\prime}(\theta) \\
\alpha_{i}\end{array}\right\} \alpha^{\prime} / \alpha$ \\
\hline $\begin{array}{l}\text { INTRINSIC } \\
\text { DISLOCATION } \\
\text { HIGH TEMP. }\end{array}$ & DKG $(\theta)$ & $\begin{array}{lll}\gamma, & \gamma_{1} & \gamma_{2}\end{array}$ & $\gamma_{(i)}$ \\
\hline $\begin{array}{l}\text { INTRINSIC } \\
\text { INTERACTION }\end{array}$ & & $\beta_{i}, \quad i=1,2,3$ & $\begin{array}{ll}\beta_{i} & (\perp) \\
\beta_{i} & (\theta)\end{array}$ \\
\hline $\begin{array}{l}\text { EXTRINSIC } \\
\text { INTERACTION } \\
\text { CORE-MOBILITY }\end{array}$ & $\begin{array}{l}\text { GKM } \\
\text { DKG }\end{array}$ & $\begin{array}{l}\alpha(V, N b, T a) \\
\text { C.W.P. } \\
S-K\end{array}$ & $\begin{array}{l}S-K^{\prime}(X), S-K^{\prime}(X, \perp) \\
S-K \quad(X), S-K \quad(X, \theta) \\
(X=H, 0, N \text { or } C)\end{array}$ \\
\hline $\begin{array}{l}\text { EXTRINSIC } \\
\text { INTERACTION } \\
\text { IMMOBILE PINS }\end{array}$ & & $\begin{array}{l}\beta_{i} \\
P_{i}\end{array}$ & $\beta_{\alpha}(x), \beta_{\gamma}(x)$ \\
\hline
\end{tabular}

Relaxation parameters so far obtained for the $\gamma$ peaks in Nb (56), Ta (33), Mo(32) $W(3), \alpha-F e(46,57,58)$ are all entirely consistent with DKG $(\Theta)$. The $\gamma$ peak narrowness and instability is taken into account by a model proposed by Astiê (58). In this model, the $\theta$ 's move by thermal activation in the internal stress field and the dislocation segments change from an initial straight position towards a bowed-out position. During this motion, the screw part of the dislocation decreases and the $\gamma$ peak disappears. This model gives a good description of the $\gamma$ behaviour in b.c.c's. 
b) Conditions of Plastic deformation.- Studies of the amount and temperature of plastic deformation on the $\alpha^{\prime} / \alpha$ and $\gamma$ peaks, particularly in Mo $(32,59)$, $W(77)$ and $\alpha-F e(58,60)$ indicate that a major component of $\alpha^{\prime} / \alpha$ is due to $\perp^{\prime} s$ and that $\gamma$ is due to $\theta^{\prime}$ s. In $\alpha-5 e$ the entire $\alpha^{\prime} / \alpha$ complex is attributed to DKG $\left(\perp(60)\right.$, which suggests that the apparent structure of $\alpha^{\prime} / \alpha$ is due to the presence of several types of $L^{\prime}$ 's with nearly equal mobilities.

c) Effects of Impurities.- In $\alpha$-Fe, the interaction of II's (other than $H$ ) with I's gives rise to $\beta_{\alpha}(60,61)$. Similar peaks are expected in the other b.c.c's but in $\mathrm{V}, \mathrm{Nb}$ and $\mathrm{Ta}$ they are probably inhibited by the interactions of 0 (or $N$ ) with residual $H$, or masked by the $S-K(H)$ relaxation. Extra interaction peaks are observed in the results of Rieu (59) on single crystals of Mo and $W$. Of these, the peak labelled $\beta_{2}$ by the author is attributed to the interaction of dislocations with unspecified impurities. In $\mathrm{Nb}(62)$ and $\mathrm{Ta}$ (fig. 15), the two components $\gamma_{1}$ and $\gamma_{2}$ that are candidates for DKG $(\theta)$ behave differently in the presence of II's. It has been reported that in $\mathrm{Nb} \gamma_{1}$ requires the presence of 0 (62), whereas in $\mathrm{Ta}, \gamma_{2}$ requires the presence of $0(33)$. In Fe, $\beta_{\gamma}(60,61)$ seems to require the presence of $C$ (or $N$ ). It is probable, that in all the b.c.c's of sufficiently high purity $\gamma$ is a symmetric single peak (see fig. 14 for Mo). In substitutionnal Fe alloys, Astié (58) has observed two peaks called $\gamma_{I}$ and $\gamma_{I I}$ (fig. 18): $\gamma_{I}$ appears around $230 \mathrm{~K}$ and $\gamma_{\text {II }}$ at about $320 \mathrm{~K}$. For dilute alloys, $\gamma_{I}$ and $\gamma_{I I}$ appear together whereas for concentrated alloys only $\gamma_{I}$ appears. The behaviour of these two peaks is quite similar to the $\gamma$ peak in pure iron.
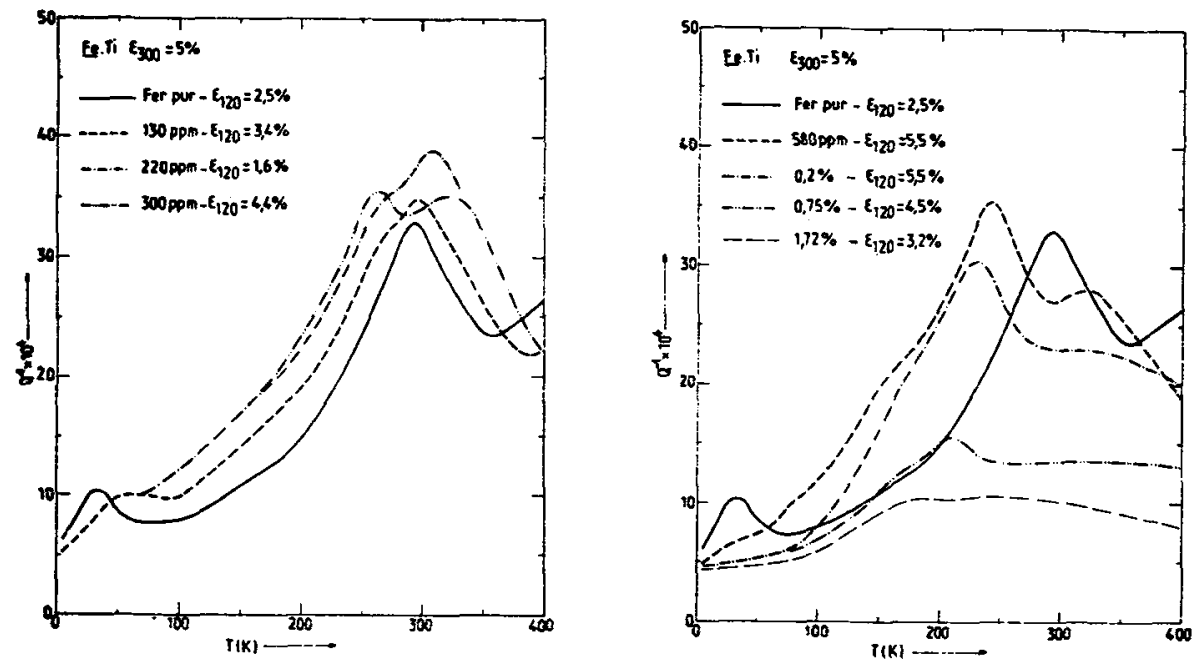

Fig. 18 : Internal friction spectra of $\mathrm{Fe}-\mathrm{Ti}$ alloys predeformed $5 \%$ at $300 \mathrm{~K}$ then deformed at $120 \mathrm{~K}$ : influence of Ti concentration (58). 
The $r_{I}$ peak is associated to DKG on softened $\theta^{\prime} s$ and the activation enthalpy measured from IF experiments is in good agreement with the values deduced from plasticity behaviour (58). The $\gamma_{\text {II }}$ peak is due to DKG on normal $\theta^{\prime} s$.

d) Effects of Irradiation.- Low temperature, low dose irradiations of predeformed b.c.c's produce similar changes to the IFS as low temperature deformation. Both create intrinsic point defects which interact with the dislocations and give rise to interaction peaks analogous to the Hasiguti peaks in the f.c.c's (3). The most detailed study of a deformed and irradiated b.c.c. is the study of $\alpha-F e$ reported by the Grenoble group $(46,60,61)$. The évolution of the IFS after $20 \mathrm{~K}$

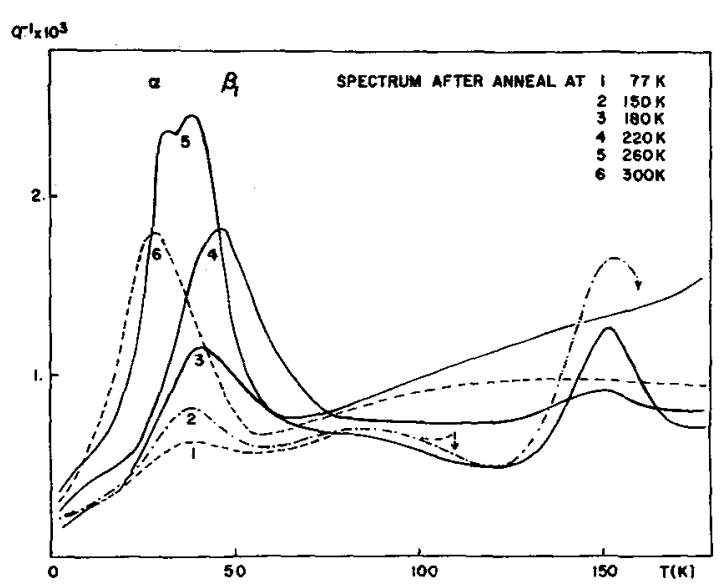

Fig. 19 : Evolution of the internal friction spectrum of deformed and electron irradiated $(20 \mathrm{~K})$ $\alpha$-Fe during successive anneals $(60,61)$. electron irradiation is shown in fig. 19 and the results of experiments comparing the low temperature irradiation with deformation are summarized in fig. 20. Generation of intrinsic point defects at low temperatures suppresses $\alpha / \alpha$ and generates $\beta_{1}$. After annealing in stage III of the recovery of electrical resistivity, the dislocations which give rise to $\alpha^{\prime} / \alpha$ are cleaned of their intrinsic point defects and $\alpha^{1 / \alpha}$ reappears. By following changes in the relaxation intensity and peak temperature of $\alpha^{\prime} / \alpha$ and $\beta_{1}$ during annealing, stages similar to those observed in the recovery of resistivity can be observed, allowing the IFS to be used as a sensitive tool in the study of radiation damage.

In $\mathrm{Nb}$ and $\mathrm{Ta}$, it is apparent that the interaction of traces of $H$ with vacancies leads to further complications $(33,45)$.

Effects of irradiation on $Y$ have not been studied in any detail. A second interaction peak, $\beta_{\gamma}$, is observed at temperatures just below $\gamma$ in $\alpha-\mathrm{Fe}(46)$. It is attributed to the dragging of a self-interstitial-type defect by geometrical kinks on $\theta^{\prime} s$.

e) Low Temperature Modulus Defect.- Changes in the dynamic elastic modui i at very low temperatures have been reported in $V(<6 K)(40), \mathrm{Nb}(<15 \mathrm{~K})(45)$, Ta $(<20 \mathrm{k})$ (33) and $\alpha-\mathrm{Fe}(<4 K)(60)$. These results are generally attributed to $\alpha^{\prime}(1)$ (i.e. $\operatorname{GKM}(\perp))$. However, in Fe there is some evidence that GKM( $\theta$ ) may be involved as $w \in 11(60)$. 
f) Effects of Oscillation Amplitude and Bias Stresses.- In the $\mathrm{Nb}$ single crystals (42), $\alpha^{\prime} / \alpha$ increases in intensity with increasing strain amplitude.

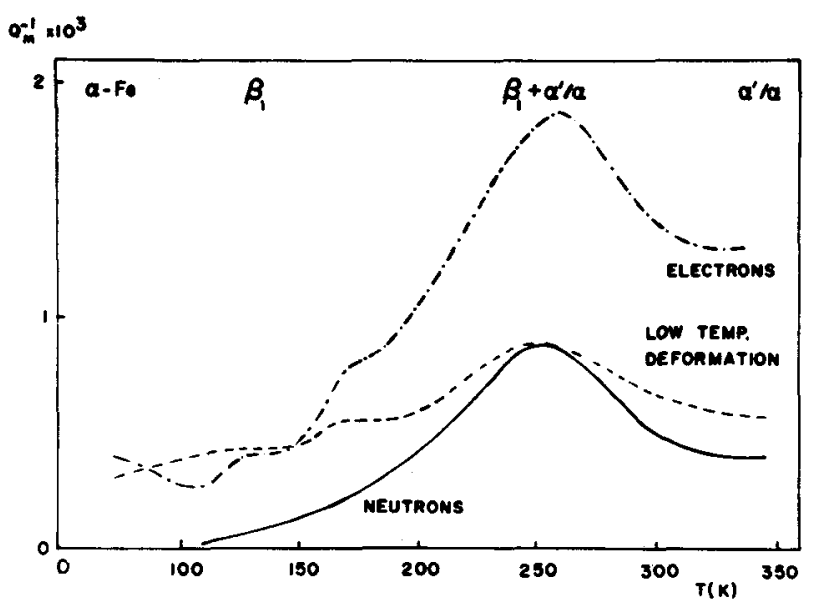

Fig. 20 : Evolution of the $\alpha^{1 / \alpha+\beta_{1}}$ complex in deformed $\alpha$-Fe following electron irradiation or supplementary cold-work at $77 \mathrm{~K}(60,61)$ or after neutron irradiation at $77 \mathrm{~K}(46)$.

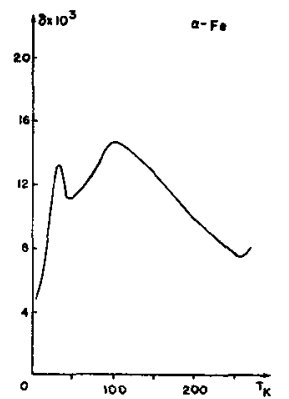

(a)

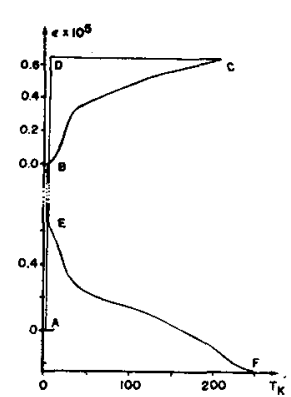

(b)

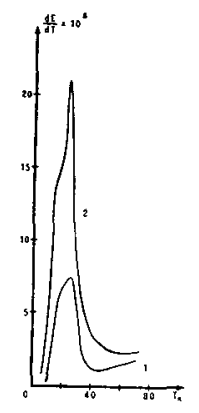

(c)
Fig. 21 : (a) IF peaks $\alpha^{1} / \alpha$ and $\beta_{\alpha}$ in Fe after $2 \%$ deformation at RT. (b) Microdeformation cycle : $A B$, loading to $\sigma_{S}=6 \times 10^{-5} ; B C$ heating under stress; $C D$, cooling under stress; $D E$, unloading; $E F$, recovery without stress; (c) Derivative curves of the $\alpha^{1 / \alpha}$ stage : $1 \sigma_{s}=3 \times 10^{-5} \mu ; 2 \quad \sigma_{s}=6 \times 10^{-5} \mu$ (64).
In $\alpha$-Fe, strain amplitude dependence occurs at $5 \times 10^{-6}$ even at $4 K$ and increases with increa : sing temperature $(61,63)$. Recent studies of the strain amplitude dependence associated with $\alpha^{\prime} / \alpha$ and $\gamma$ in Mo single crystals (32) yield activation volumes of 30-150 $b^{3}$ for the major component of $\alpha^{\prime} / \alpha$ and $\sim 50 b^{3}$ for $\gamma$. These results are entirely consistent. with DKG (L) and DKG $(\Theta)$ respectively.

Increasing strain amplitude causes the intensity of $\gamma$ in $\mathrm{Nb}$ to increase (62) and bias stresses increase the high temperature background. These results are analogous to those reported for the Bordoni relaxation (3).

g) Microdeformation.Microdeformation stages associated with $\alpha^{\prime} / \alpha$ (see fig. 21) and $\gamma$ $(58,65)$ have been reported recently. The results obtained using a torsion pendulum technique can be summarized as follows i) the activation volume associated with $\alpha$ is in the range 10 to $100 \mathrm{~b}^{3}$ 
in keeping with DKG ( $)$; ii) a substructure corresponding to $\alpha^{\prime}$ is observed but has not been analysed in detait; iii) the recovery stage $\left(\alpha_{r}\right)$ (see fig. 20) (b)) in the absence of stress is always at a lower temperature than stage $\alpha$; iv) a microdeformation stage is also associated with $\beta_{\alpha}$ but its characteristics are such that it is not amenable to the same type of analysis used in the case of stage $\alpha$; and $v)$ the stage associated with $\gamma(58,65)$ can be correlated with the zero-pointdrift of the pendulum in conventional studies of the IF peak $\gamma$ and the results confirm that $\theta^{\prime}$ s are responsible for both the microdeformation stage and peak $\gamma$. Furthermore, the model proposed by Astiē et a]. (65) (see 3.2.4. a) can aiso describe the $\gamma$ microdeformation in b.c.c's.

3.2.5 Summary.- The If peaks $\alpha / \alpha$ and $\gamma($ at $\simeq 1 \mathrm{~Hz})$ are illustrated

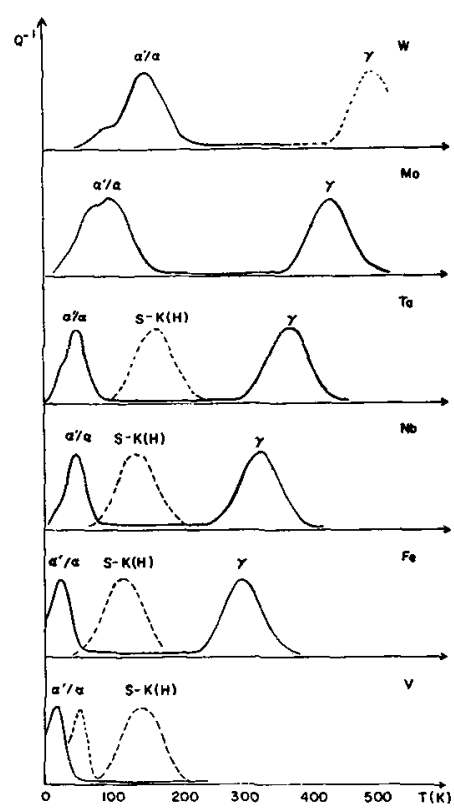
schematically (together with the $S-K(H)$ peaks) in fig. 22. In Mo, $W$ and $\alpha-F e, \alpha^{\prime} / \alpha$ contains a major component due to DKG (Ц), whereas in $V$, $\mathrm{Nb}$ and Ta containing significant amounts of both $H$ and 0 (or $N$ ) it seems that DKG (D) is pinned-out and $\alpha^{3} / \alpha$ (previously $\delta$ ) is predominantly due to GKM $(\theta)$. However, in UHP $N b$ a major component of $\alpha^{\prime} / \alpha$ is attributed to DKG ( $\perp$ ). In $V, \mathrm{Nb}$, Ta and $\alpha-\mathrm{Fe}$ there is a good evidence that $\alpha^{\prime}(\perp)$ occurs below the lowest temperatures yet investigated.

Fig. 22 : Shematic diagram showing the relative positions and shaped of the $\alpha^{1 / \alpha}$ and $\gamma$ peaks at about $1 \mathrm{~Hz}$ in ultra high purity b.c.c. transition metal.

Although no one b.c.c. has been studied to the extent that all the primary and secondary characteristics of the BR (3) have been confirmed for both $\alpha^{\prime} / \alpha$ and $r$; each of the characteristics is exhibited by one or more of the b.c.c. metals taken as a group. Now, there can be little donbt that $\alpha^{1 / \alpha}$ and $\gamma$ taken together contain the analogue of the $B R$ in the f.c.c's.

Acknowledgements. - The authors wish to thank Prof. H. Schultz, P. Groh, C. Minier, M. Koiwa and Dr. C. Esnouf, J. Lauzier, L.B. Magalas who kindly made results of their groups' investigations available prior to publication. 


\section{References}

(1) P.G. BORDONI, Ric. Sci. 19, 851, 1949; J. Acoust. Soc. Am. 26, 495, 1954.

(2) A. SEEGER, Phi1. Mag. 1, 651, 1956; J. Phys. 32, C2-193, 1971.

(3) G. FANTOZZI, C. ESNOUF, W. BENOIT and I. RITCHIE, Prog. Mat. Science to be published.

(4) A. SEEGER, Phys. Stat. Soi. 55(a), 457; 1979.

(5) J.P. HIRTH, Met. Trans. A, 11A, 861, 1980.

(6) V.K. PARE, J. App1. Phys. 32, 332, 1961.

(7) H. ENGELKE, Phys. Stat. Sol. 36, 231, 1969.

(8) C. ESNOUF and G. FANTOZZI, Phys. Stat. SoT.(a), 47, 201, 1978.

(9) J. SCHLIPF and R. SCHINDLMAYR, Phi1. Mag. A, 40, 1, 13, 1979.

(10) A.D. BRAILSFORD, Phys. Rev. 122, 778, 1961 and 128, 1033, 1962.

(11) C. WUTHRICH, Scripta Met. 9, 641, 1975.

(12) G. SCHOECK, Acta Meta 11. 11, 617, 1963.

(13) L. VERDINI and D. BACCI, Nuovo Cimento 59B, 1, 163, 1980.

(14) R.E. MINER, R. GIBALA and F.A. HULTGREN, Acta Meta11. 24, 233, 1976.

(15) D. WAGNER and F. STANGLER, 6th ICIFUAS, ed. by R.R. Hsiguti.and N. Mikoshiba, p. 585 (1977). University of Tokyo Press.

(16) P. STADELMANN and W. BENOIT, Scripta Met. 11, 645, 1977.

(17) W. BENOIT, G. FANTOZZI and C. ESNOUF, Nuovo Cimento 33B, 1, 1976.

(18) G. FANTOZZI, F. FOUQUET and P.F. GOBIN, Scripta Met. 7, 53, 1973.

(19) T. JALANTI, Thesis, E.P.F. Lausanne, 1975.

(20) S.M. SEYED-REIHANI, Thesis, University of Lyon, 1981.

(21) J. LAUZIER and C. MINIER, this conference.

(22) D.0. THOMPSON and D.K. HOLMES, J. Appl. Phys., 30, 525, 1959.

(23) J.L. BESSON, Thesis, University of Limoges, 1977.

(24) Ph. DETERRE, C. ESNOUF, G. FANTOZZI, P. PEGUIN, J. PEREZ, I.G. RITCHIE,

F. VANONI and A. VINCENT, Acta Met. 27, 1779, 1989

(25) G. ALEFELD, J. App 1. Phys. 36, 2642, 1965.

(26) G. GREMAUD, Thesis, Lausanne, 1981.

(27) C. ESNDUF and G. FANTOZZI, Phil. Mag. A, 42, 63, 1980.

(28) B. ESCAIG, Scripta Meta11. 5, 199, 1971.

(29) A. SEEGER and B. SESTAK, Scripta Meta11. 5, 875, 1971.

(30) P.C. GEHLEN - Interatomic potentials and Simulation of Lattice Defects, Battelle Colloquium, edited by J.R. BEELER and R.J. JAFFEE, Plenum Press, New-York, 1971 p. 475.

(31) H. SCHULTZ, M. MAUL, U. RODRIAN and R. GRAU, Proc. 5th International Symposium on "High Purity Materials in Science and Technology" edited by J. Morgenthal and H. Oppermann, Dresden GDR, Vol. III, 334, 1980.

R. GRAU, Doctoral Thesis, Stuttgart, 1981.

(33) U. RODRIAN, Doctoral Thesis, Stuttgart, 1980.

(34) E. PINK and R.J. ARSENAULT, Prog. Mat. Science 24, 1, 1, 1979.

(35) F.M. MAZZOLAI and M. NUOVO, Sol. Stat. Comm. 7, 103, 1969.

(36) R. KLAM, H.E. SCHAEFER and H. SCHULTZ, Proc. 6th ICIFUAS, Tokyo 1977, Edited by R.R. Hasiguti and N. Mikoshiba, University of Tokyo Press, 1977, p. 599.

G. CANNELLI and F.M. MAZzOLAI, J. Phys. Chem. Solids, 31, 1913, 1970. L.J. BRUNER, Phys. Rev., 118, 2, 399, 1960.

K. SHIBATA, M. KOIWA and 0. YOSHINARI, Trans. J.I.M. 19, 491, 1978.

(40) H. MIZUBAYASHI, S. OKUDA and M. DAIKUBARA, Scripta Meta11. 13, 1131, 1979.

G. FERRON, M. QUINTARD and P. MAZOT, Scripta Meta11. 12, 623, 1978.

(42) N. KURAMOCHI, H. MIZUBAYASHI and S. OKLLA, Scripta Metai1. 14, 1047, 1980.

(43) L. VERDINI and D. BACCI, Nuovo Cimento 59B, 1, 163, 1980.

(44) M. MAUL and H. SCHULTZ, this conference.

(45) M. MAUL, Doctoral Thesis, Stuttgart, 1980.

(46) V. HIVERT, P. GROH, P. MOSER and W. FRANK, Phys. Stat. Sol. 42(a), 511, 1977.

(47) R. MARTINEZ, F. WALZ and H. KRONMULLER, App 1. Phys. 7, 107, 1975.

(48) H. KRONMULLER, H. STEEB and N. KONIG, Nuovo Cimento, 33B, 205, 1976.

(49) T.S. KE, H. KRONMULLER, A. SEEGER and 2.Q. Sun, Proc. 3rd Int. Conf. on the Effect of Hydrogen on the behaviour of Materials, Jackson Lake Lodge, Wyoming, Aug. 1980. 
(50) I.G. RITCHIE, J.F. DUFRESNE and P. MOSER, Phys. Stat. Sol. 52(a), 331, 1979.

(51) K. TAKITA, M.NIIKURA and K. SAKAMOTO, Scripta Metall. 14, 1047, 1980.

(52) A.J. KUMMICK and H.H. JOHNSON, Acta Metal1. 28, 33, 1980.

(53) J.F. DUFRESNE, A. SEEGER, P. GROH and P. MOSER, Phys. Stat. Sol . 36(a), 579, 1976 .

(54) J. VOLKL and G. ALEFELD, Topics in Applied Physics 28, Hydrogen in Metals 1, chapter 12. Edited by G. ALEFELD and J. VöLKL, Springer-Verlag, Berlin, 1978.

(55) N. IGATA, N. KURAMOCHI, N. MASAMURA, A. KOHYAMA, K. MIYAHARA, S. SATO and H. YOSHIDA, Phys. Stat. So1. 55(a), K 127, 1979.

(56) DE LIMA, Thesis, E.P.F. Lausanne, 1981.

(57) M.SHIMAOA and K. SAKAMOTO, Scripta Metai1. 13, 1177, 1979.

(58) P. ASTIE, Thesis, Toulouse, 1981.

(59) G.E. RIEU, Acta Meta 17. 26, 1, 1978.

(60) I.G. RITCHIE, J.F. DUFRESNE and P. MOSER, Phys. Stat. Sol. 50(a), 617, 1978.

(61) J.F. DUFRESNE, I.G. RITCHIE and P. MOSER, Proc. 3rd E.C.I.F.U.A.S., Manchester 1979. Edited by C.C. Smith, Pergamon Press, 1980, p. 37.

(62) N. IGATA, H. MURAKANI and N. MASAMURA, Scripta Metali. 14, 463, 1980.

(63) M. KAKEGOWA and K. SAKAMOTO, Jap. J. App1. Phys, 9, 1057, 1970.

64) J. SANJUAN, $L$. NO, G. FANTOZZI, C. ESNOUF and $F$. VANONI, this conference.

(65) P. ASTIE, J.P. PEYRADE and P. GROH, Scripta Metal1., to be published. 